\title{
EFEKTIFITAS PENERAPAN STANDAR ASUHAN KEPERAWATAN JIWA GENERALIS PADA PASIEN SKIZOFRENIA DALAM MENURUNKAN GEJALA HALUSINASI
}

\author{
Satria Fajrullah Said Aldam*, Ice Yulia Wardani \\ Fakultas Ilmu Keperawatan, Universitas Indonesia \\ *fajrulaldam@gmail.com
}

\begin{abstract}
ABSTRAK
Halusinasi merupakan persepsi yang diterima oleh panca indera tanpa adanya stimulus eksternal. Klien dengan halusinasi sering merasakan keadaan/kondisi yang hanya dapat dirasakan olehnya namun tidak dapat dirasakan oleh orang lain. Tujuan laporan kasus ini yaitu untuk menganalisis mengenai tandar asuhan keperawatan generalis pada pasien skizofrenia dalam menurunkan gejala halusinasi. Karya ilmiah akhir ini merupakan analisis terhadap pelaksanaan asuhan keperawatan pada pasien halusinasi dengan skizofrenia yang dilakukan di Ruang Srikandi Rumah Sakit dr. H. Marzoeki Mahdi Bogor. Hasil analisis menunjukkan bahwa ntervensi keperawatan secara generalis sangat efektif diberikan pada pasien dengan gangguan sensori persepsi halusinasi pendengaran. Hal ini ditandai dengan penurunan tanda gejala halusinasi pada klien setelah diberikannya tindakan keperawatan.
\end{abstract}

Kata kunci: asuhan keperawatan jiwa generalis, halusinasi, skizofrenia

\section{EFFECTIVENESS OF THE IMPLEMENTATION OF STANDARDS FOR NURSING GENERALIS NURSING AT SKIZOFRENIA PATIENTS IN REDUCING HALUSINATION SYMPTOMS}

\begin{abstract}
Hallucinations are perceptions received by the five senses in the absence of an external stimulus. Clients with hallucinations often feel the conditions / conditions that can only be felt by him but can not be felt by others. The purpose of this case report is to analyze the level of generalist nursing care in schizophrenic patients in reducing hallucinatory symptoms. This final scientific work is an analysis of the implementation of nursing care in hallucinatory patients with schizophrenia conducted in the Srikandi Room of Dr. dr. H. Marzoeki Mahdi Bogor. The results of the analysis showed that general nursing intervention was very effective given to patients with sensory disorders of auditory hallucinations perception. This is marked by a decrease in hallucinatory symptoms to the client after nursing is given.
\end{abstract}

Keywords: generalist mental nursing care, hallucinations, schizophrenia

\section{PENDAHULUAN}

Kesehatan jiwa yang positif memiliki tiga komponen yakni kesejahteraan emosional, psikologis, dan sosial (Keyes, 2002). Kesehatan jiwa dipengaruhi oleh faktor predisposisi dan presipitasi. Menurut Stuart, Keliat, dan Pasaribu (2016) faktor predisposisi adalah jenis dan jumlah koping yang dipengaruhi oleh faktor risiko dan faktor protektif. Sedangkan faktor presipitasi adalah suatu stimulus yang diberikan dan dapat membuat individu merasa tertantang dan terancam sehingga menyebabkan stres. Stresor pada faktor presipitasi dapat bersifat biologis, psikologis, dan sosial. Selain itu, stressor tersebut dapat berasal dari lingkungan internal dan eksternal individu. Lingkungan yang menyebabkan stres berulang dalam rentang waktu yang berdekatan akan menyebabkan individu sulit dalam mengatasinya. Dengan demikian, individu harus mampu dalam mengatasi stres yang terjadi atau jika tidak maka akan berdampak gangguan dalam kejiwaannya. 
Menurut WHO (2004) jumlah penderita gangguan jiwa diperkirakan mencapai 450 juta jiwa. Pernyataan lain dari Rabba, Dahrianis, \& Rauf (2014) terdapat 8,1\% masyarakat mengalami gangguan jiwa di dunia. Menurut Prevalensi gangguan jiwa berat di Indonesia yakni sebanyak 7 per mil (Riskesdas, 2018). Gangguan jiwa berat adalah gangguan jiwa yang ditandai dengan kemampuan menilai realitas yang buruk. Gangguan jiwa berat dikenal dengan sebutan psikosis dan salah satu contoh psikosis adalah skizofrenia. Gejala yang menyertai pada gangguan jiwa berat yaitu waham, ilusi, gangguan proses pikir, agresivitas, dan halusinasi.

Skizofrenia adalah bentuk psikis yang di dalamnya terdapat gangguan utama yaitu pada bagian proses pikir yang tidak seimbang antara proses pikir, cara pikir, bahasa, dan perilaku (Direja, 2011). Gejala skizofrenia dibedakan menjadi dua yaitu gejala positif dan gejala negatif. Gejala negatif dari skizofrenia yakni kehilangan motivasi atau apatis, depresi yang tidak ingin ditolong. Sedangkan gejala positif meliputi waham, delusi, dan halusinasi.

Menurut Stuart, Keliat, dan Pasaribu (2016) halusinasi merupakan distrosi persepsi yang tidak nyata dan terjadi pada respons neurobiologis maladaptive. Halusinasi yang dialami oleh individu dapat disebabkan melalui faktor presdisposisi dan presipitasi. Hal ini didukung oleh pernyataan dari Stuart, Keliat, \& Pasaribu (2016) penyebab munculnya halusinasi ada dua yaitu faktor predisposisi dan presipitasi. Faktor predisposisi terdiri dari (1) faktor biologis yang berhubungan dengan perkembangan sistem saraf yang tidak normla, (2) Faktor psikologis seperti pola asuh orang tua, kondisi keluarga dan lingkungan, (3) Faktor sosial budaya seperti kondisi ekonomi, konflik sosial, serta kehidupan yang terisolasi disertai stres. Sedangkan faktor lainnya yaitu presipitasi yakni (1) faktor biologi yang terkait dalam gangguan komunikasi dan putaran balik otak yang mengatur proses informasi, (2) Faktor lingkungan yang mana terjadi tingkat stresor lingkungan di luar batas toleransi individu, (3) Koping yang dapat menentukan seseorang dalam mentoleransi stresor.

Klien dengan halusinasi yang telah dikendalikan oleh halusinasinya akan melakukan perilaku yang membahayakan dirinya, orang lain, dan juga lingkungan. Pernyataan ini didukung oleh penelitian Scott (2017) pada usia 14 - 21 tahun terdapat peningkatan dalam risiko bunuh diri, psikopatologi psikopat, dan nonpsikotik sehingga sulit dalam mencari pekerjaan yang berakibat menurunnya kualitas hidup. Penanganan secara tepat untuk mengatasi dampak dari halusinasi yakni dengan melakukan tindakan asuhan keperawatan. Menurut Stuart, Keliat, \& Pasaribu (2016) asuhan keperawatan yang diberikan pada penderita halusinasi bertujuan untuk meningkatkan kesadaran pasien antara stimulasi persepsi yang dialami pasien dan kehidupan nyata. Selain tindakan asuhan keperawatan, terdapat Auditory Hallusination Symptomp Management (AHSM) yang memiliki efek yang baik untuk memperbaiki dan mengurangi gejala dari halusinasi dan depresi pada pasien skizofrenia.

Kasus nyata terjadi pada pasien halusinasi yang dialami oleh Nn. A berusia 30 tahun dan ini merupakan kali pertama dirawat di RSMM. Klien dibawa ke RSMM karena keluyuran di jalan, marah-marah, keluarga mengatakan bahwa kegiatan klien di rumah yakni jarang makan, malas mandi, tidak mau mengerjakan pekerjaan apapun, dan hanya tidur-tiduran serta berdiam diri di kamar. Klien juga mengatakan bahwa di rumah hanya tidurtiduran karena suara-suara yang mengatakan dirinya tidak mampu untuk beraktivitas. Pengkajian dilakukan pada tanggal 18 Maret 2019 didapatkan klien mengatakan dirinya ingin pulang karena ada suara-suara yang mengatakan bahwa dirinya bukan pasien dan harus pulang hal tersebut membuat klien menjadi cemas. Selain itu, adapun suara-suara yang mengatakan bahwa klien bodoh, tidak dapat beraktivitas, pelacur, dan orang-orang tidak akan suka terhadap dirinya. Saat melakukan interaksi nada suara klien sangat pelan, kontak mata minimal, dan sering menggosok-gosok tangan ke hidung. Klien tampak bersih, mondar-mandir, dan sering berdiam diri di kamar. Untuk mengatasi halusinasi pada Nn. A di ruang Srikandi, perawat memberikan terapi stimulasi persepsi dalam mengontrol halusinasi yang terdiri dari 4 sesi yaitu (1) mengahrdik dengan menutup telinga atau mengajak klien untuk konsentrasi 
dan yakin dalam hati bahwa dirinya mampu untuk menghilangkan halusinasi, (2) mengontrol halusinasi dengan patuh minum obat, (3) mengajak klien untuk mengobrol dengan orang lain, (4) mengajak klien untuk melakukan aktivitas yang paling disukai yaitu mewarnai. Evaluasi dilakukan untuk mengetahui perkembangan klien dan memastikan bahwa intensitas halusinasi dapat berkurang. Selain itu, mengevaluasi cara mengontrol halusinasi yang paling dirasakan klien tepat untuk dipilih dalam menghardik halusinasi.

\section{METODE}

Karya ilmiah akhir ini merupakan analisis terhadap pelaksanaan asuhan keperawatan pada pasien halusinasi dengan skizofrenia yang dilakukan di Ruang Srikandi Rumah Sakit dr. H. Marzoeki Mahdi Bogor.

\section{HASIL}

Hasil pengkajian dan observasi dilakukan pada tanggal 25 Maret 2019. Nn. A (30 tahun) masuk ke RS dr. H. Marzoeki Mahdi pada tanggal 18 Maret 2019 dengan diagnosis medis skizofrenia hebefrenik. Kakak klien mengatakan bahwa klien sebelum mederita gangguan jiwa memang sangat jarang untuk bergaul dengan teman-teman sebayanya, tidak memiliki sahabat atau teman, masalah yang dialami hanya disimpan sendiri, dan hanya berdiam diri di kamar. Alasan klien tidak ingin memiliki teman karena beranggapan bahwa anak-anak seumurannya ketika berteman pasti gibahin orang lain dan ia tidak suka dengan hal itu. Kakak klien juga mengatakan bahwa keadaan yang tidak harmonis di dalam keluarga dapat membuat kondisi mental klien menjadi terganggu.

Keluarga mengatakan bahwa tante klien juga mengalami gangguan jiwa dengan gejala yakni dapat merasakan aliran darah dan luka pada kaki yang hanya dirasakan oleh dirinya sendiri. Pengalaman masa lalu klien yang tidak menyenangkan yaitu ditolak dari lingkungan masyarakat ketika ingin berinteraksi. Selain itu juga, klien pernah drop out dari kampusnya saat semester tiga. Mekanisme koping klien tergolong maladaptif karena ketika ada masalah atau stresor yang dilakukan yakni menghindar. Klien mengatakan bahwa dirinya sering mendengar suara-suara. Klien mengatakan bahwa halusinasinya datang lebih dari $8 x$ /hari dan tidak menentu waktunya. Situasi yang menyebabkan halusinasi yaitu saat dirinya sedang bengong, melamun, atau sendiri. Klien juga mengatakan bahwa saat halusinasi datang dirinya menjadi cemas, marah-marah, dan bingung.

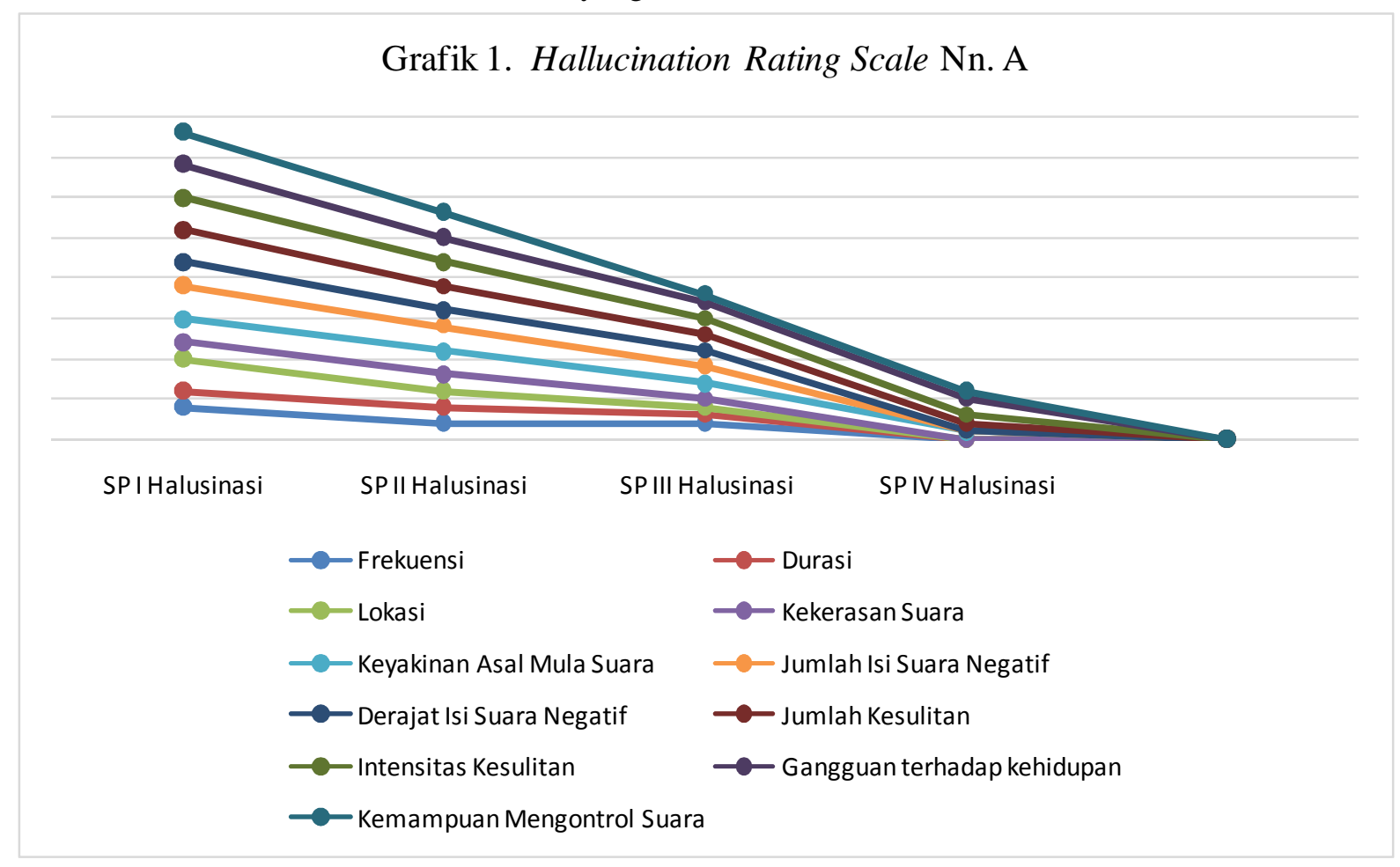


Pada grafik 1 dapat terlihat bahwa dari strategi pelaksanaan I - IV dengan diagnosis gangguan sensori persepsi: halusinasi pendengaran, seluruh item yang berada pada hallucination rating scale yang merupakan gejala halusinasimengalami penurunan. Dengan demikian, asuhan keperawatan jiwa generalis dengan diagnosis gangguan sensori persepsi: halusinasi pendengaran dapat diterapkan dalam menurunkan gejala halusinasi.

\section{PEMBAHASAN}

Kejadian gangguan jiwa pada Nn. A sesuai dengan Videbeck (2011) yakni skizofrenia rentan terjadi pada rentang usia remaja akhir hingga dewasa awal. Menurut WHO (2016) terdapat 21 juta jiwa di dunia mengalami skizofrenia. Meskipun skizofrenia hebefrenik bukan merupakan jenis yang paling sering terjadi, namun menjadi tiga besar skizofrenia yang sering terjadi dengan presentase $12 \%$ (Sumekar \& Zahina, 2016). Riskesdas (2018) menjelaskan bahwa kejadian gangguan jiwa berat di Indonesia mengalami kenaikan dari 1,7 mil menjadi 9 mil dengan rentang usia diatas 15 tahun. Dengan demikian, terlihat bahwa kejadian skizofrenia telah dapat dialami pada individu dengan rentang usia remaja akhir hingga dewasa awal.

Berdasarkan gambaran kasus Nn. A pada saat remaja tidak memiliki teman dekat yang dapat diajak ngobrol. Selain itu, saat di rumah aktifitas klien hanya tidur dan jarang berkomunikasi dengan anggota keluarga. Hal ini tentu mempengaruhi kesehatan jiwa klien. Aldam \& Keliat (2018) menjelaskan bahwa terdapat hubungan yang bermakna antara masalah dalam keluarga dan masalah dengan teman sebaya terhadap kesehatan jiwa remaja. Masalah dengan teman sebaya yang terjadi pada klien dapat mempengaruhi tugas perkembangan klien saat masa remaja. Kozier, Berman, \& Snyder (2012) menjelaskan bahwa remaja akan sering menghabiskan waktu bersama dengan temna-temannya untuk mengetahui identitasnya. Hal ini sesuai dengan pernyataan dari Wong (2009) bahwa tugas perkembangan remaja yaitu pencarian identitas diri. Menurut Hidayat, Keliat, \& Mustikasari (2014) tugas perkembangan yang tidak terselesaikan pada usia sebelumnya akan menjadi stresor untuk perkembangan berikutnya dan stresor yang menumpuk akan berisiko terhadap gangguan jiwa.

Faktor predisposisi secara biologis yang dimiliki oleh klien yakni tante klien mengalami gangguan jiwa. Individu yang memiliki hubungan dengan tingkat pertama (orang tuan, saudara atau keturunan) atau tingkat kedua (kakek-nenek, bibi-paman, sepupu, cucu) dengan penderita akan lebih rentan mengalami gangguan jiwa (Stuart, Keliat, dan Pasaribu, 2016). Klien juga mengalami hubungan dengan orang tua yang tidak harmonis. Komunikasi dalam keluarga yang tidak berjalan secara efektif juga dialami oleh klien. Orang tua juga tidak pernah membahas dan membantu menyelesaikan masalah yang dialami oleh klien. Hubungan yang buruk antara orang tua dengan anak dan disfungsi peran keluarga dapat berpengaruh terhadap kejadian gangguan jiwa (Townsend, 2008).

Faktor presipitasi secara psikologis yang mempengaruhi kejadian gangguan jiwa pada klien yakni pengalaman yang tidak menyenangkan seperti penolakan dari masyarakat saat melakukan interaksi dan perasaan bersalah karena tidak mampu untuk merawat almh. mama pada saat sakit. Keltner, Bostom, \& McGuinness (2011) menjelaskan bahwa stresor psikologis yang dapat berpengaruh terhadap kejadian gangguan jiwa yaitu rasa bersalah, berduka dan kehilangan, perasaan takut akan penolakan. Stresor secara sosial budaya seperti stres akibat masa perkuliahan dapat berdampak pada kejadian gangguan jiwa (Halter, 2014).

Keadaan stres pada individu yang tidak diselesaikan melalui strategi koping yang baik dapat mengakibatkan gangguan jiwa (Videbeck, 2011). Saat terjadinya gangguan jiwa juga klien memiliki mekanisme koping yang kurang baik. Klien memiliki mekanisme koping secara emosi. Hal ini dapat terlihat dengan keadaan klien yang terkadang asik atau sering cemas saat halusinasi muncul. Trimelia (2011) menjelaskan bahwa mekanisme koping yang berfokus pada emosi akan menyebabkan klien menjadi asik dengan isi dari halusinasi.

Pasien dengan halusinasi pendengaran biasanya melaporkan keadaannya seperti mendengar kebisingan, bisikan yang 
mengobrol dengan dirinya, dan bisikan yang memerintahkan pasien untuk berbuat kekerasan terhadap orang lain ataupun dirinya sendiri (Videbeck, 2011). Saat halusinasi datang yang dilakukan pasien yaitu marahmarah, cemas, dan mondar-mandir.

Menurut Stuart, Keliat, \& Pasaribu (2016) model stres adaptasi Stuart berfokus terhadap respon klien saat mengalami stres dan membantu klien dalam pemahaman mengenai tujuan dan proses yang akan dilakukan pada tindakan keperawatan. Nyumirah, Keliat, dan Helena (2013) menjelaskan bahwa sangat efektif dalam penggunaan model pendekatan Stuart dikarenakan perawat dapat mendeskripsikan keadaan klien dan menggambarkan proses terjadinya gangguan jiwa khususnya gangguan sensori persepsi halusinasi.

Pada pertemuan pertama yang dilakukan yakni bina hubungan saling percaya pada klien. Bina hubungan saling percaya dapat berjalan dengan efektif dengan menggunakan komunikasi terapeutik. Kozier, Berman, \& Snyder (2012) menjelaskan bahwa penerapan komunikasi terapeutik dapat membuat pasien puas terhadap pelayanan keperawatan. Allender, Rector, \& Warner (2014) menjelaskan bahwa komunikasi yang efektif secara interpersonal untuk menimbulkan rasa percaya klien yakni dengan bersikap empati dengan keadaan klien yang perawat temui. Dengan demikian, agar dapat membuat pasien menjadi percaya dan menceritakan apa yang dirasakan perlu bagi perawat untuk bersikap empati.

Pengendalian halusinasi yang dapat diterapkan pada pasien yakni menghardik, bercakapcakap, berkegiatan sesuai jadwal yang telah dibuat, dan mengonsumsi obat secara teratur (Keliat, 2012). Menghardik halusinasi pendengaran yang muncul dapat dilakukan dengan menutup telinga dan menolak adanya halusinasi. Selain itu, dapat dilakukan dengan konsentrasi, yakin dalam hati bahwa klien dapat menghilangkan halusinasi, dan kemudian menolak halusinasi. Hal ini juga sejalan dengan penelitian yang mengatakan bahwa dengan cara menghardik dapat menurunkan intensitas halusinasi pada klien (Zelika \& Dermawan 2015; Wati, 2018).
Teknik dalam mengendalikan halusinasi berikutnya yaitu bercakap cakap yang dilakukan pada pertemuan ketujuh. Direja (2011) mengatakan bahwa salah satu cara yang dapat menurunkan intensitas halusinasi yakni dengan melakukan interaksi atau bercakapcakap. Berdasarkan penelitian dijelaskan bahwa dengan melakukan interaksi dapat mengubah fokus klien terhadap halusinasi ke interaksi yang dilakukan sehingga halusinasi dapat terputus (Chien \& Chan 2013; Zelika \&Dermawan 2015; Wati, 2018).

Keluarga mengatakan bahwa saat berada di rumah klien tidak minum obat secara teratur. Klien dengan tidak minum obat secara teratur dapat menyebabkan halusinasi terjadi secara berulang. Riskesdas (2018) menjelaskan bahwa 51,1\% pasien dengan skizofrenia tidak rutin minum obat. Nyumirah, Keliat, \& Helena (2013) menjelaskan bahwa 70\% faktor presipitasi klien dengan putus obat dapat mengalami halusinasi kembali. Setelah mendapatkan tindakan mengenai edukasi patuh obat kepada klien, klien mampu untuk menyebutkan delapan benar obat, nama dan manfaat dari obat yang dikonsumsi dengan bantuan perawat. Pengendalian halusinasi yang telah diberikan oleh klien perlu dilakukan juga kepada keluarga agar pengobatan dapat dilakukan saat klien berada di rumah.

Pemberian asuhan keperawatn pada klien dengan gangguan sensori persepsi tidak terlepas dari pengawasan keluarga. Hal ini sesuai dengan pernyataan yang dikemukakan oleh Videbeck (2011) yakni keluarga merupakan bagian terpenting yang mendukung pasien untuk menyelesaikan masalah halusinasinya. Keluarga juga perlu mengetahui perasaan dan kedaan klien disetiap harinya saat berada di rumah. Pernyataan tersebut didukung oleh Friedman (2010) bahwa fungsi afektif pada keluarga merupakan kebutuhan psikososial yang diinginkan oleh anggota keluarga meliputi kehangatan, cinta kasih, saling mengasuh, dan saling mendukung antaranggota keluarga.

Intervensi lain yang dapat dilakukan dengan pasien yang mengalami halusinasi pendengaran berdasarkan Auditory Hallucination Symtomp Management (AHSM) yaitu mendengarkan musik, membaca, 
melakukan aktivitas, menutup salah satu telinga, relaksasi tarik napas dalam dan relaksasi otot tanpa menghilangkan minum obat secara rutin (Yang et al, 2015). Tindakan asuhan keperawatan generalis pada pasien dengan gangguan sensori persepsi halusinasi memiliki dampak positif yang ditandai dengan penurunan gejala halusinasi dan pengembangan kemampuan kognitif dan psikomotor klien ketika mengalami halusinasi (Nyumirah, Keliat, \& Helena, 2013).

Gejala halusinasi muncul saat klien memiliki respon negatif pada stresor yang dialaminya. Pengukuran tanda gejala dari halusinasi meliputi respon kognitif, afektif, perilaku, dan sosial. Respon kognitif klien setelah diberikan tindakan keperawatan yaitu konsentrasi yang baik ditandai dengan berkurangnya intensitas klien untuk menjawab pertanyaan perawat dengan jawaban tidak tahu dan tidak bisa. Perubahan respon kognitif yag dialami oleh klien merupakan dampak dari perawat yang terlatih dalam mengendalikan halusinasi pasien. Hal ini sesuai dengan pernyataan dari Carolina \& Keliat (2008) bahwa respon kognitif yang positif pada klien dengan gangguan sensori persepsi halusinasi dapat terjadi akibat peran perawat yang terlatih.

Respon afektif klien sebelum mendapatkan tindakan keperawatan yaitu perasaan takut, cemas, dan selalu meminta untuk pulang. Setelah mendapatkan tindakan keperawatan, intensitas perasaan takut dan cemas klien berkurang. Komunikasi yang baik dan terapi yang sesuai dapat menurunkan respon negatif dari pasien dengan halusinasi (Fadly \& Keliat, 2017). AHSM menjelaskan bahwa pemberian terapi tarik napas dalam memiliki keefektifan emosi yang positif pada pasien dengan halusinasi pendengaran.

Respon perilaku yang dialami klien sebelum mendapatkan tindakan keperawatan yakni klien tampak bingung dan malas untuk mengikuti aktivitas di ruangan. Setelah dilakukan tindakan keperawatan, respon perilaku klien yakni tampak tenang dan mampu untuk mengikuti aktivitas di ruangan namun butuh motivasi oleh perawat. Menurut Stuart, Keliat, \& Pasaribu (2016) respon maladaptif neurobiologis salah satunya yaitu kebingungan dan perlu mendapatkan obat antipsikotik dengan tujuan untuk mengoptimalkan penyembuhan klien. AHSM menjelaskan bahwa terapi napas dalam, menutup sebelah telinga, dan minum obat secara rutin dalam modifikasi perilaku pada pasien juga dapat menurunkan intensitas halusinasi pendengaran yang dialami pasien.

Respon sosial yang dimiliki pada klien sebelum mendapatkan tindakan keperawatan yaitu sulit untuk mengikuti kegiatan di ruangan dan di rumah tidak pernah mengikuti kegiatan dalam masyarakat. Tindakan yang dilakukan perawat untuk mengatasi masalah klien yaitu memotivasi klien untuk mengikuti kegiatan di ruangan seperti terapi aktivitas kelompok. Tujunnya agar intensitas klien dalam berkomunikasi dengan perawat dan klien lain menjadi lebih sering. Respon sosial klien mengalami perubahan ke arah positif. Keliat, Akemat, Helena, \& Nurhaeni (2011) menjelaskan bahwa pemberian kesempatan untuk pasien dalam melakukan kegiatan sosialisasi seperti terapi aktivitas kelompok dapat membentuk respon positif pada keadaan sosial klien.

\section{SIMPULAN}

Klien yang mengalami gangguan sensori persepsi halusinasi pendengaran dengan diagnosis medis skizofrenia hebefrenik. Intervensi keperawatan secara generalis sangat efektif diberikan pada pasien dengan gangguan sensori persepsi halusinasi pendengaran. Hal ini ditandai dengan penurunan tanda gejala halusinasi pada klien setelah diberikannya tindakan keperawatan. Rencana tindak lanjut dalam penelitian selanjutnya yakni mengenai tindakan keperawatan dengan cara melakukan motivasi terhadap kegiatan yang terjadwal pada pasien dengan halusinasi. Tujuannya untuk menurunkan gejala dari halusinasi dan menyempitkan waktu pasien dalam memikirkan halusinasi.

\section{DAFTAR PUSTAKA}

Wati, Niken Ika. (2018). Asuhan Keperawatan Pada Klien Dengan Gangguan Sensori Persepsi: Halusinasi Pendengaran Di Rumah Sakit Dr. H. Marzoeki Mahdi Bogor. Karya Ilmiah Akhir Ners. Universitas Indonesia. Tidak Dipublikasi 
Keyes, C. L. M. (2002). The Mental Health Continuum : From Languishing to Flourishing in Life. Journal of Health and Social Behavior, 43(6), 207-222. https://doi.org/10.2307/3090197

Rabba E.P., Rauf S.P., \& Dahrianis. (2014). Hubungan antara Pasien Halusinasi Pendengaran Terhadap Resiko Perilaku Kekerasan Di Ruang Kenari RS Khusus Daerah Provinsi Sulawesi Selatan. Jurnal Ilmiah Kesehatan Diagnosa Vol. 4, No. 4.

Stuart, G. W., Keliat, B. A., \& Pasaribu, J. (2016). Prinsip dan praktik keperawatan kesehatan jiwa stuart. Edisi Indonesia. Singapore: Elsevier

WHO. 2018. Schizophrenia. Diakses melalui http://www.who.int/mental_health/mana gement/schizophrenia/en/ pada 02 Mei 2018

Kemenkes RI. (2018). Riset kesehatan dasar (RISKESDAS) 2018. Laporan Nasional 2018. Jakarta: Badan Penelitian dan Pengembangan Kesehatan KementrtianKesehatan RI.

Direja, A. H. A. (2011). Asuhan Keperawatan Jiwa. Nuha Medika: Yogyakarta

Choong C, Hunter M.D., Woodruff P.W. (2007). Auditory hallucinations in those populations that do not suffer from schizophrenia. Curr Psychiatry Rep.

Videbeck, S.L. (2008). Buku ajar keperawatan jiwa. Jakarta: EGC

WHO. (2016). Schizophrenia. Retrieved from http://www.who.int/mediacentre/factshe ets/fs397/en/

Townsend, M. C. (2009). Essentials of psychiatric mental health nursing: concepts in care in evidence-based practice. 6th ed. Philadelphia: Davis Company

Kozier, B., Berman, A., \& Snyder, S. (2012). Kozier \& 7 erb's fundamental of nursing: concepts, process, and practice. New Jersey: Pearson Education, Inc.
Hidayat, E Keliat,B.K, Wardani (2011). Pengaruh Cognitive Behavioral Therapy (CBT) dan Rational Emotive Behavioral Therapy (REBT) terhadap klien dengan perilaku kekerasan dan harga diri rendah Di RS Dr. H. Marzoeki Mahdi Bogor. Tesis. Tidak Dipublikasikan.

Keltner, N. L., Bostrom, C. E., \& McGuinness, T. M. (2011). Psychiatric nursing (6th ed.). St. Louis: Mosby Elsevier.

Halter, M. J. (2014). Varcarolis' foundation of psychiatric mental health nursing (7th ed.). St. Louis: Saunders Elsevier

Stuart, G.W. \& Laraia, M.T. (2005). Principle and practice of psychiatric nursing (8th ed.). Philadelphia, USA: Mosby, In.

Trimelia. (2011). Asuhan keperawatan klien halusinasi. Jakarta: CV Trans Info Media.

Waters, F. (2009). Auditory Hallucinations in Psychiatric Illness. Psychiatric Times, 14, 62-65.

Nyumirah, S., Keliat, B.A., \& Helena. N. (2013). Manajemen asuhan keperawatan spesialis jiwa pada klien dengan halusinasi di Ruang Sadewa di Rumah Sakit Dr. H. Marzoeki Mahdi Bogor. Tugas Akhir Profesi FIK UI.

Keliat, B. A., Akemat, Daulima, N. H. C, \&Nurhaeni. (2011). Keperawatan kesehatan jiwa komunitas CMHN (basic course). Jakarta: Penerbit Buku Kedokteran EGC.

Allender, J. A., Rector, C., \& Warner, K. D. (2014). Community \& Public Health Nursing : Promoting the Public's Health (8th Ed). Philadelphia: Wolters KluwerHealth Lippincott Williams \& Wilkins.

Zelika A.A., Dermawan D. 2015. Kajian Asuhan Keperawatan Jiwa Halusinasi Pendengaran pada Saudara D di Ruang Nakula RSJD Surakarta. Jurnal Profesi Vol. 12, No. 2. 
Chien, W. T., \& Chan, Z. C. Y. (2013). Chinese translation and validation of the questionnaire on the process of recovery in schizophrenia and other psychotic disorders. Research in Nursing \& Health, 36(4), 400-411. http://dx.doi.org/10.1002/nur.21549

Fadly, M., Keliat, B.A., Susanti, H., \& Wardani, I.Y. (2017). Hubungan kesejahteraan spiritual dengan gejala halusinasi pada klien skizofrenia di rumah sakit jiwa. Skripsi. Depok: Universitas Indonesia.

Friedman, M.M., Bowden, O., \& Jones, M. (2010). Buku ajar keperawatan keluarga: Riset, teori, \& praktik: alih bahasa, Achir Yani S Hamid, et al., editor bahasaIndonesia, Estu Tiar, Ed. 5. Jakarta: EGC.

Carolina., Keliat, B.A. (2008). Pengaruh Penerapan Standar Asuhan Keperawatan Halusinasi Terhadap Kemampuan Klien Mengontrol Halusinasi di RS Jiwa Dr. Soeharto Heerdjan Jakarta. Tesis. Universitas Indonenesia. Tidak Dipublikasi. 